\title{
FUNGOS VEICULADOS POR SEMENTES COMERCIAIS DE BRAQUIÁRIA
}

\author{
C.E. Marchi ${ }^{1}$, C.D. Fernandes ${ }^{2}$, M.L. Bueno ${ }^{3}$, M.V. Batista ${ }^{2}$, L.R. Fabris ${ }^{4}$
}

${ }^{1}$ Laboratório Nacional Agropecuário (Lanagro/SP/MAPA), Av. Jundiaí, 773, CEP 13208-051, Jundiaí, SP, Brasil.E-mail: carlos.marchi@agricultura.gov.br

\section{RESUMO}

Este trabalho objetivou avaliar a qualidade sanitária de 50 lotes comerciais de sementes de braquiária, produzidos em diferentes regiões nas safras de 2004-2005 e 2005-2006. Sementes de Brachiaria brizantha cvs. Marandu e Xaraés, B. decumbens cv. Basilisk, B. humidicola cv. Humidicola e B. ruziziensis cv. Ruziziensis, destinadas ao comércio interno, foram submetidas ao teste de sanidade pelo método de papel de filtro. Adicionalmente, avaliou-se a sanidade de sementes de 'Marandu' (2 lotes) e 'Basilisk' (1 lote) destinadas à exportação. As sementes foram distribuídas sobre papel de filtro acondicionado em gerbox e incubadas a $20^{\circ} \mathrm{C}$, com fotoperíodo de $12 \mathrm{~h}$, durante sete dias. Os fungos secundários ou de armazenamento (FSA) mais frequentemente detectados nos lotes de braquiária foram Aspergillus sp. e Rhizopus sp. Quanto aos fungos potencialmente patogênicos (FP), constatou-se elevada frequência dos gêneros Bipolaris, Curvularia, Fusarium e Phoma. Em geral, foi elevada a incidência de Bipolaris sp., Fusarium sp. e Phoma sp. nas sementes. A ocorrência de Phoma sp. foi crítica, pois $42 \%$ dos lotes registraram índices superiores a 70\%. Bipolaris sp., Fusarium sp. e Phoma sp. também foram associados às sementes de braquiária tipo exportação, em alguns casos, com incidência considerável. Os resultados revelaram que as sementes comerciais de braquiária apresentam baixa qualidade sanitária e que, em todas as regiões produtoras, existe pelo menos um fator afetando a sanidade dessas sementes.

PALAVRAS-CHAVE: Brachiaria spp., patologia de sementes, micoflora, qualidade sanitária.

\section{ABSTRACT}

FUNGI ASSOCIATED TO COMMERCIAL SEED OF BRAQUIARIA GRASS. This work aimed to evaluate the sanitary quality of 50 commercial lots of seeds of braquiaria grass, produced in different regions in the crop of 2004-2005 and 2005-2006. The lots consisted of seeds of the cultivars Brachiaria brizantha cvs. Marandu and Xaraes, B. decumbens cv. Basilisk, B. humidicola cv. Humidicola and B. ruziziensis cv. Ruziziensis. Additionally, seeds of 'Marandu' (2 lots) and 'Basilisk' (1 lot) for exportation were analyzed. The blotter test was used, at $20^{\circ} \mathrm{C}$ under alternating light and darkness in a $12 \mathrm{~h}$ photoperiod, for 7 days. Aspergillus sp. and Rhizopus sp. were the secondary or storage fungi with greatest frequency in lots of seeds. High frequency of potential pathogenic fungi, specifically of the Bipolaris, Curvularia, Fusarium and Phoma genera, was observed. In general, there was a high incidence of Bipolaris sp., Fusarium sp. and Phoma sp. in braquiaria grass seeds. The occurrence of Phoma sp. was severe, because $42 \%$ of the lots showed incidence superior to $70 \%$. Bipolaris sp., Fusarium sp. and Phoma sp. were associated to braquiaria grass seeds for exportation, in some cases, with significant incidence. The results evidenced the low sanitary quality of commercial seeds of braquiaria grass, and demonstrated that in all producer regions there is at least one factor affecting the sanitary quality of these seeds.

KEY WORDS: Brachiaria spp., pathology of seeds, mycoflora.

${ }^{2}$ Embrapa Gado de Corte, Laboratório de Fitopatologia, Campo Grande, MS, Brasil.

${ }^{3}$ Universidade Federal de Mato Grosso do Sul, Departamento de Biologia, Campo Grande, MS, Brasil.

${ }^{4}$ Universidade Federal de Mato Grosso do Sul, Departamento de Clínica Cirúrgica, Campo Grande, MS, Brasil. 


\section{INTRODUÇÃO}

A qualidade da semente constitui fator determinante para o estabelecimento e a persistência das pastagens tropicais. No entanto, é frequente a utilização de lotes de sementes de baixa qualidade (genética, fisiológica e sanitária), com excesso de resíduosvegetais, soloe/ou sementes deoutras forrageiras einvasoras. Alguns fatores têm contribuído para essa realidade, entre eles: a ausência de padrões para a produção e comercialização de sementes mais restritivos, a falta de fiscalização efetiva e a indiferença do pecuarista que, ao se basear no preço por quilograma como critério para aquisição de sementes, nãoestimula a adequação do setor (MARCHI et al., 2006a).

Quanto à qualidade sanitária, especificamente, pouco se conhece sobre os patógenos associados às sementes de forrageiras tropicais produzidas e comercializadas no país (FERNANDES et al., 2005). Sobretudo fungosenematoides fitopatogênicos têm sido detectados nas sementes. A associação de patógenos às sementes representa impacto significativo para o setor, pois estes podem afetar o estabelecimento do estande, o desenvolvimento das plantas, a produção de sementes, a persistência das forrageiras no campo e, consequentemente, a produção de leite e carne bovina. Além dos danos diretos, a presença desses micro-organismos prejudica as exportações de sementes forrageiras (VECHIATO, 2004; FERNANDES et al., 2005). Visto que as sementes contaminadas constituem mecanismo eficiente de introduçãoe dispersão de patógenos, a presença destes em lotes de sementes de braquiária tem resultado na imposição de barreiras fitossanitárias pelos países importadores.

Tabela 1 - Relação dos lotes (L) de sementes comerciais de Brachiaria sp. submetidos à análise sanitária e as respectivas origens e ano de produção.

\begin{tabular}{|c|c|c|c|}
\hline \multirow[t]{2}{*}{ Forrageira } & \multirow[t]{2}{*}{ Lote (L) } & \multicolumn{2}{|c|}{ Origem } \\
\hline & & SAFRA 2004-2005 & SAFRA 2005-2006 \\
\hline \multirow{9}{*}{ Brachiaria brizantha cv. Marandu } & 1 & Paraíso, MS & Costa Rica, MS \\
\hline & 2 & Camapuã, MS & Rio Verde, GO \\
\hline & 3 & Barreiras, BA & Rio Verde, GO \\
\hline & 4 & Rio Verde, GO & Paraíso, MS \\
\hline & 5 & Luis Eduardo Magalhães, BA & Chapadão do Sul, MS \\
\hline & 6 & Rio Verde, GO & NI \\
\hline & 7 & Luis Eduardo Magalhães, BA & Rio Verde, GO \\
\hline & 8 & Costa Rica, MS & Camapuã, MS \\
\hline & 9 & Uberlândia, MG & - \\
\hline \multirow{7}{*}{ B. brizantha cv. Xaraés } & 1 & Bandeirantes, MS & Piquerobi, SP \\
\hline & 2 & Santo Anastácio, SP & Tupaciguara, MG \\
\hline & 3 & Montes Claros, MG & Jales, SP \\
\hline & 4 & Camapuã, MS & Chapadão do Sul, MS \\
\hline & 5 & Jales, SP & Água Clara, MS \\
\hline & 6 & Paraíso, MS & Paraíso, MS \\
\hline & 7 & Costa Rica, MS & - \\
\hline \multirow{4}{*}{ B. decumbens cv. Basilisk } & 1 & Camapuã, MS & Camapuã, MS \\
\hline & 2 & Cajurú, SP & Cássia de Coqueiros, SP \\
\hline & 3 & Camapuã, MS & Costa Rica, MS \\
\hline & 4 & Paraíso, MS & Paraíso, MS \\
\hline \multirow{4}{*}{ B. humidicola cv. Humidicola } & 1 & Quirinópolis, GO & Terenos, MS \\
\hline & 2 & $\mathrm{NI}^{*}$ & Água de Santa Bárbara, SP \\
\hline & 3 & - & Nova Alvorada do Sul, MS \\
\hline & 4 & - & Pedro Gomes, MS \\
\hline \multirow{4}{*}{ B. ruziziensis cv. Ruziziensis } & 1 & NI & Paraíso, MS \\
\hline & 2 & Tupaciguara, MG & Correntina, BA \\
\hline & 3 & - & Luis Eduardo Magalhães, BA \\
\hline & 4 & - & Tangará da Serra, MT \\
\hline
\end{tabular}

${ }^{*} \mathrm{NI}=$ não informado. 
Com relação à microflora fúngica, importantes patógenos têm sido detectados em sementes de braquiária, como Claviceps maximensis eUstilago operta, agentes etiológicos da mela-das-sementes e do carvão, respectivamente(MARCHI et al.,2007; MARCHI et al., 2008). Adicionalmente, a presença de Magnaporthe grisea, fungo altamente destrutivo, foi verificada em sementes de B. brizantha cv. Marandu, no Estado do Pará (BENCHIMOl et al., 2006). Fungos potencialmente patogênicos (FP) como Bipolaris sp., Curvularia sp., Drechslera sp., Exserohilum sp., Fusarium sp. e Phoma sp., e fungos considerados secundários ou de armazenamento(FSA) como Alternaria sp.,Aspergillus sp., Cladosporium sp., Epicoccum sp., Nigrospora sp., Penicillium sp. e Trichoderma sp. também ocorrem frequentementeem sementes debraquiária(VECHIATO, 2004; FERNANDEs et al., 2005; MARCHI et al., 2006a).

A escassez de informações acerca dos fungos veiculados por meio das sementes comerciais de braquiária tem contribuído para o aumento da incidência de doenças nas áreas de pastagens. Visando ampliar esse conhecimento, objetivou-se analisar a microflora fúngica de lotes sementes das principais cultivares de Brachiaria sp., produzidas em diferentes regiões do país e comercializadas no mercado interno, e também de lotes de sementes com alta pureza física, destinados ao mercado externo.

\section{MATERIALEMÉTODOS}

Amostras de lotes (L) comerciais de sementes de Brachiaria spp., destinadas ao mercado interno, foram fornecidas por empresas do setor. Tais sementes foram produzidas nas safras de 2004-2005 e 2005-2006, em várias regiões produtoras do país (Tabela 1).

Adicionalmente, foram analisados alguns lotes comercias de sementes com alta pureza genética, produzidos na safra 2004-2005. Estes incluíram dois lotes de sementes de B. brizantha cv. Marandu, (Lote1, produzido em Rio Verde, GO; Lote 2, origem não informada) e um lote de B. decumbens cv. Basilisk, composto por sementes produzidas em Costa Rica, MS e Uberlândia, MG.

Para a identificação da micoflora das sementes utilizou-se o método do papel de filtro (Blotter Test). Para isso, foram utilizadas 200 sementes de cada cultivar, divididas em 10 repetições (20 sementes / repetição). As sementes foram mantidas sobre o papel de filtro estéril umedecido com água destilada e esterilizada, dentro de caixa tipo gerbox. Em seguida, procedeu-se à incubação das sementes por sete dias a temperatura de $20^{\circ} \mathrm{C}$ e fotoperíodo de $12 \mathrm{~h}$ (MARTINS et al., 2001). Após a incubação, realizou-se a identificação da microflora fúngica das sementes sob microscópio estereoscópico e de luz. Quando necessário, recorreu-se à literatura pertinente para auxílio na identificação dos fungos.

Os procedimentos estatísticos foram realizados com o auxílio dos programas SAS (SAS InSTITUTE, 1997) e Genes (CRUZ, 2001). Para atender as pressuposições da ANAVA, os dados deincidência (\%) defungosnas sementes foram transformados para $\sqrt{(x+0,01)}$. Contudo, para a melhor interpretação dos resultados, foram apresentadas as médias dos dados originais. As comparações múltiplas entre as médias foram realizadas pelos testes de Tukey ou agrupamento de Sсотт; Клотт (1974), a 5\% de probabilidade.

Otermo "fungos potencialmentepatogênicos" foi designado aos fungos capazes de incitar doença em forrageiras tropicais, ou que, embora não demonstrado, apresentam potencial para tanto. Otermo "fungos secundários ou de armazenamento" foi atribuído aos fungos que apresentam menor importância econômica para as forrageiras tropicais ou que podem ser responsáveis pela deterioração de sementes no período de armazenamento.

\section{RESULTADOSEDISCUSSÃO}

A microflora fúngica associada aos lotes de sementes comerciais de braquiária está descrita na Tabela 2. Muitos desses fungos foram detectados anteriormente em sementes de Brachiaria spp., inclusive em amostras de sementes comerciais (LASCA et al., 2004; FERnANDEset al.,2005; MARChi et al.,2006b; MORAES et al., 2006; Silva et al., 2006).

Aspergillus sp. e Rhizopus sp. foram os FSA mais frequentementedetectadosnoslotes desementes (Tabela 2). Os fungos Cladosporium sp., Epicoccum sp., Nigrospora sp.e Penicillium sp. também foram detectados nos lotes nas duas safras. A. niger, Botrytis sp. e Trichoderma sp. não estavam presentes nos lotes produzidos em 2004-2005. Em contrapartida, Pithomyces sp. foi detectado apenas nos lotes desta safra, cujo índice de frequência foi $41,7 \%$. A ocorrência desse gênero nos lotes comerciais de sementes constitui fato relevante, visto que a espécie $P$. chartarum tem sido associada a casos de fotossensibilização hepática em bovinos (FIORAVANTE, 1999; SOARES et al., 2000).

Quanto aos FP, todos os lotes transportavam Bipolaris sp. e Phoma sp. (Tabela 2). Também foram elevadas as frequências de lotes portadores dos gêneros Fusarium e Curvularia. A ampla dispersão desses FP tem sido garantida pela ausência de padrões de qualidade sanitária para a comercialização das sementes e pela falta de produtos registrados para o tratamento seu. Com respeitoà Rhizoctonia sp., maior frequência (29,2\%) foi observada na safra 2004-2005. Na safra posterior, esse patógeno ocorreu em 7,7\% dos lotes analisados. 
Tabela 2 - Frequência de lotes comerciais de sementes de braquiária (Brachiaria brizantha 'Marandu', 'Xaraés', B. decumbens 'Basilisk', B. ruziziensis 'Ruziziensis' e B. humidicola 'Humidicola'), produzidos em diferentes regiões do Brasil nas safras 2004-2005 e 2005-2006, portadores de fungos.

\begin{tabular}{lcc}
\hline Fungo & \multicolumn{2}{c}{ Frequência (\%) } \\
\cline { 2 - 3 } & Safra 2004-2005 & Safra 2005-2006 ${ }^{2}$ \\
\hline Alternaria alternata & 37,5 & 26,9 \\
Aspergillus sp. & 95,8 & 96,2 \\
Aspergillus niger & 0,0 & 23,1 \\
Bipolaris sp. & 100,0 & 100,0 \\
Botrytis sp. & 0,0 & 7,7 \\
Cladosporium sp. & 58,3 & 57,7 \\
Curvularia sp. & 87,5 & 100,0 \\
Epicoccum sp. & 66,7 & 53,8 \\
Fusarium sp. & 95,8 & 96,2 \\
Nigrospora sp. & 58,3 & 46,2 \\
Penicillium sp. & 29,2 & 42,3 \\
Phoma sp. & 100,0 & 100,0 \\
Pithomyces sp. & 41,7 & 0,0 \\
Rhizoctonia sp. & 29,2 & 7,7 \\
Rhizopus sp. & 79,2 & 76,9 \\
Trichoderma sp. & 0,0 & 3,8 \\
\hline
\end{tabular}

${ }^{1}$ Vinte e quatro lotes de sementes.

${ }^{2}$ Vinte e seis lotes de sementes.

Em geral, os fungos dearmazenamentoincidemem sementesrecém-colhidasesemanifestam, comumente, em porcentagem muito baixa (TANAKA et al., 2001). De fato, na maioria dos lotes constatou-se baixa incidência dessa categoria de fungos e daqueles considerados secundários (Tabelas $3 \mathrm{e} 4$ ). Contudo, em alguns casos, evidenciou-sealta porcentagem desementes veiculando FSA, sobretudo nos lotes de 'Humidicola'. O L2 dessa cultivar, safra 2005-2006, por exemplo, foi composto por sementes com alta incidência de Aspergillus sp. $(51,0 \%)$ e Rhizopus sp., (95,5\%) (Tabela 4). Tais índices foram preocupantes, pois fungos dos gêneros Aspergillus e Rhizopus, saprófitos cosmopolitas, típicos de armazenamento, são conhecidos por ocasionar deterioração de sementes, culminando com a redução da germinação e vigor (CIRIO; LIMA, 2003; BARRETO et al., 2004). Nesses casos, a alta incidência de FSA nas sementes podeestar relacionada ao manejo da colheita e pós-colheita, bem como à umidade relativa do ar durante o armazenamento (FARIAS et al., 2002).

Por outro lado, constatou-se elevada incidência de FPnassementes debraquiária, exceçãofeitaa Rhizoctonia sp.,queocorreuesporadicamenteeembaixaincidência $(<1,0 \%)$ (Tabelas3e4). Tais fungosocorremnoscampos deproduçãoe,emgeral,estão presentes durantegrande partedociclodacultura. Emespecial, foram detectados lotes com até $87,5 \%$ de incidência de Bipolaris sp. (L4 de 'Xaraés', safra 2005-2006) (Tabela3) e58,0\% deincidên- cia de Fusarium sp. (L3 de 'Xaraés', safra 2004-2005) (Tabela 4). A presença de Curoularia sp. também foi crítica em alguns lotes, sobretudo na safra 2005-06, quando se registrou incidência de 75,0\% (L3 de 'Humidicola') (Tabela4). A ocorrência de Phomasp.nas sementes de braquiária foi mais acentuada, pois em 21 dos 50 lotes analisados se constataram percentuais superiores a 70\%. No L2 de 'Marandu' eL4 de 'Basilisk' (safra 2005-2006), por exemplo, a porcentagem de sementes veiculando Phoma sp. foi de 90,5\% (Tabela 4).

A elevada incidência deFP nas sementes pode ser decorrente das condições favoráveis ao desenvolvimento destes nas regiões produtoras. Ouso sucessivo da mesma área e/ou de campos com histórico de FP para a produção de sementes também explicaria tais índices, visto que essa prática promove o incremento do inóculo no campo (CAMPBELL; MADDEN, 1990). Em média, os lotes analisados foram provenientes de áreas com dois anos de cultivo. No entanto, alguns lotes, sobretudo de 'Humidicola', foram oriundos de campos cultivados por três a cinco anos.

Os altos níveis de incidência de FP constituíram motivode preocupação, pois, enquantoalguns fungos são capazes de reduzir a viabilidade das sementes (NeERGAARD, 1979), outros com crescimento rápido e agressivocomoFusarium sp.ePhomasp.podem promover a morte da semente antes mesmo da germinação (Menten, 1995). Ademais, existem relatos acerca da transmissão de FP por meio de sementes. Bipolaris sorokiniana, por exemplo, é altamente transmissível pela semente, a qual constitui a principal fonte de inóculo (Pierobom; Del Ponte, 2008). Desta forma, o aumento da frequência de Bipolaris sp. nas pastagens (MARCHI etal.,2006a) poderia, em parte, estar associado à utilização de lotes de sementes contaminados. A transmissão de Fusarium sp., Phomasp. eCurvulariasp. pormeiodesementestambém foireportada(Lascaetal., 2004; MichalsKi et al., 2007). Phoma sp., em especial, podeafetaraemergênciaeprovocaramortedeplântulas debraquiária (LASCA et al., 2004), ou resultarem mudas comsintomasseveros de doença (GARCIA;PINEDA, 2000).

Em certos casos, não foram observadas diferenças significativas entre os lotes de sementes quanto à incidência de FP específicos. Na safra 2004-2005, a ocorrência de Phoma sp. nas sementes não permitiu a discriminação dos lotes de 'Xaraés', tampouco de 'Basilisk' ou 'Ruziziensis' (Tabela3). Lotes de 'Basilisk' ou 'Ruziziensis' também apresentaram níveis similares de incidência de Fusarium sp. Em adição, lotes de 'Ruziziensis' não diferiram entre si quanto à presença de Bipolaris sp. ou Curoularia sp. nas sementes. Por sua vez, na safra 2005-2006, não foram detectadas diferenças entre os lotes de 'Humidicola' ou 'Ruziziensis' quanto à incidência de Fusarium sp. (Tabela 4). Nessa última cultivar também nãose contatou discriminação entre os lotes quanto à incidência de Phoma sp. 
Fungos veiculados por sementes comerciais de braquiária.

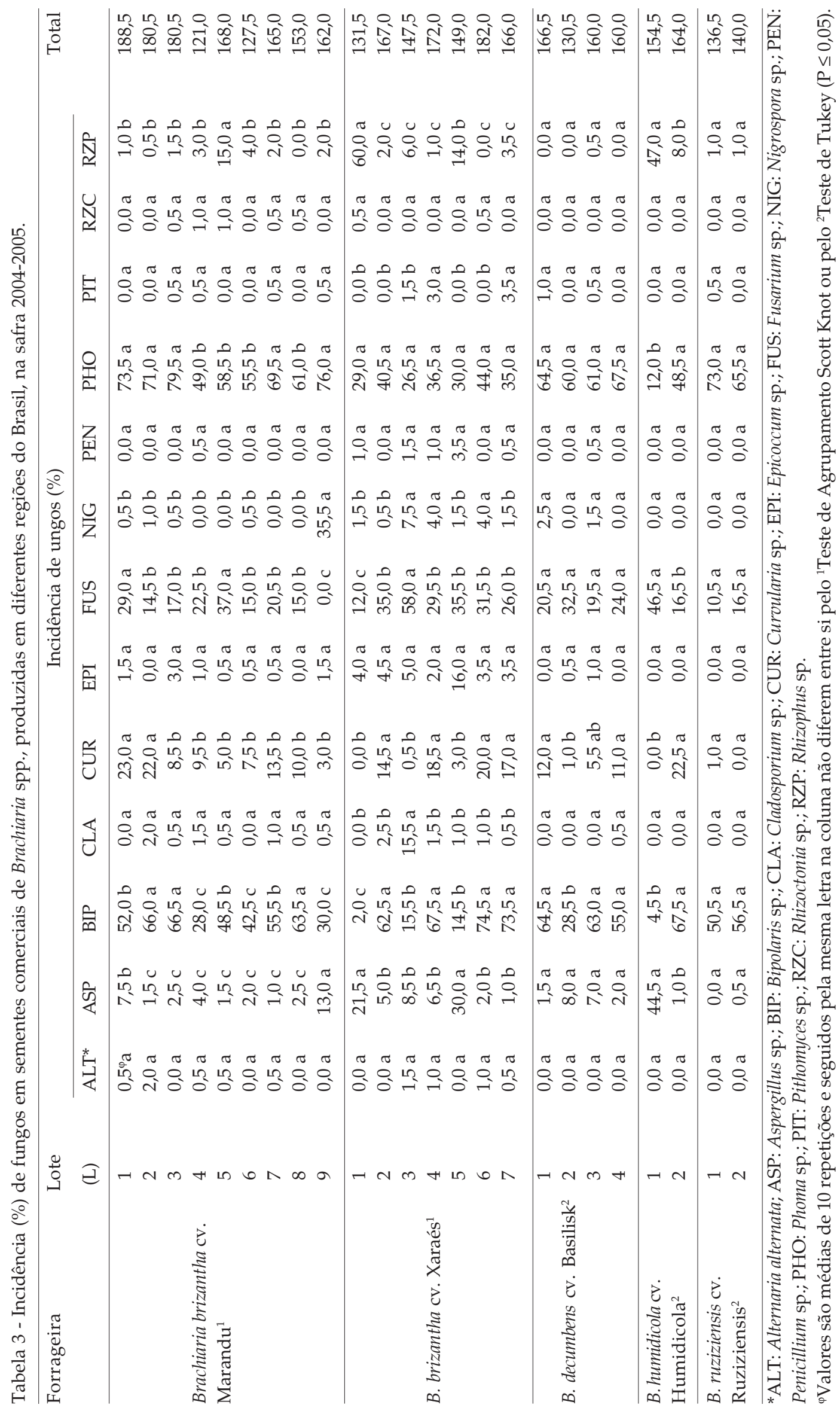




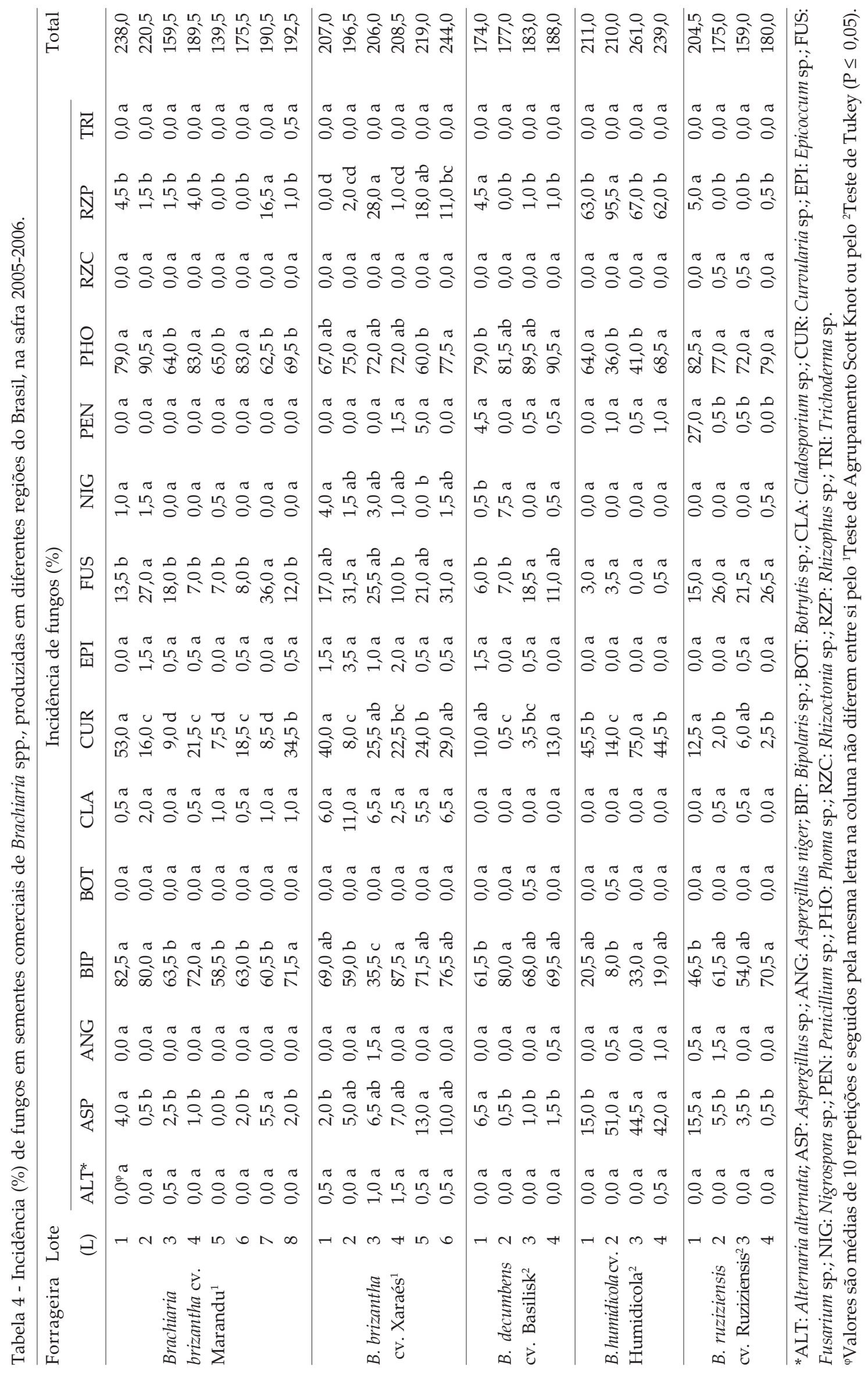


Com base na incidência total de FSA e FP nas sementes de braquiária produzidas em 2004-2005, verificou-se melhor qualidade sanitária nos lotes L4 de 'Marandu', L1 de 'Xaraés', L2 de 'Basilisk', L1 de 'Humidicola' e L1 de 'Ruziziensis' (Tabela3). Os lotes L1, L6, L1, L2 e L2 de 'Marandu', 'Xaraés', 'Basilisk', 'Humidicola' e 'Ruziziensis', respectivamente, foram os que apresentaram menor qualidade sanitária. Na safra 2005-2006, constatou-se melhor desempenho sanitário no L5 de 'Marandu', L2 de 'Xaraés', L1 de 'Basilisk', L2 de 'Humidicola' e L3 de 'Ruziziensis' (Tabela 4). Já as sementes de 'Marandu', 'Xaraés', 'Basilisk', 'Humidicola' e 'Ruziziensis' com menor qualidade sanitária corresponderam aos lotes L1, L6, L4, L3 e L1, respectivamente.

Apesar de, em ambas as safras, constatar-se sementes com sanidade diferenciada, nenhuma das respectivas regiões produtoras se destacou, pois, em cada uma delas existiu pelo menos um fator afetando negativamente a sua qualidade sanitária.Sobretudo, a alta e homogênea incidência de Phoma sp. limitou a produção de sementes de braquiária com boa qualidade sanitária (Tabelas 3 e 4).

A qualidade sanitária das sementes de braquiária com alta pureza física, produzidas na safra 20042005 e destinadas ao comércio externo, está demonstrada na Figura 1. Com relação aos FSA, verificou-se apenas a presença de Rhizopus sp. nas sementes de 'Marandu', cuja maior incidência (2,0\%) foi observa- da no L2. Os lotes de sementes de braquiária com alta pureza física também veicularam FP, entre os quais prevaleceram Bipolaris sp., Fusarium sp. e Phoma sp. (Fig. 1). Tais fungos foram detectados em todos os lotes de analisados. Considerando a incidência total de FSA e FP, o lote 1 de 'Marandu' foi o que demonstrou melhor qualidade sanitária entre as cultivares de braquiária.

A melhor qualidade física (pureza acima de $90,0 \%$ ) dos lotes de sementes destinados ao comércio externo, ou seja, o menor conteúdo de impurezas como resíduos vegetais e solo, não implicou em menores percentuais de incidência de FP nas sementes. Fusarium sp., por exemplo, incidiram em 21,0\% das sementes do lote 2 de 'Marandu' (Fig. 1). A presença de patógenos nas sementes destinadas ao mercado internacional pode constituir entrave às exportações brasileiras, pois muitos países importadores impõem restrições fitossanitárias. A presença de Claviceps spp. nos lotes de sementes de gramíneas, por exemplo, constitui barreira fitossanitária nas transações comerciais com o México (Alves; Dias, 2000).

Os resultados tornaram evidentea necessidade de adequação nas práticas de manejo dos campos produtivos, das técnicas de colheita, beneficiamento e armazenamento, no sentido de contribuir para a melhoria da qualidade sanitária das sementes comerciais de braquiária.

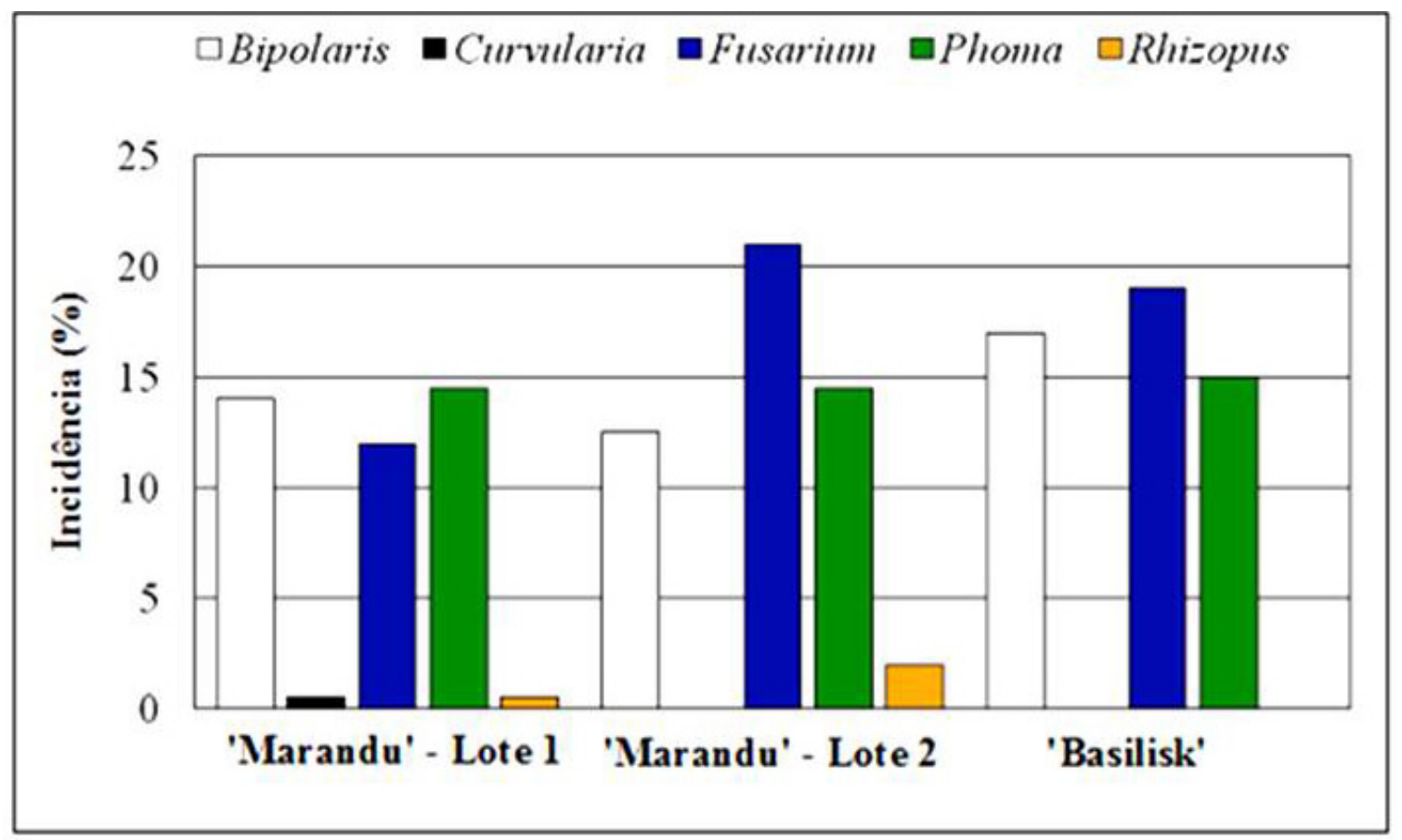

Fig. 1 - Incidência (\%) de fungos em sementes comerciais de Brachiaria brizantha cv. Marandu e B. decumbens cv. Basilisk, com alta pureza física, produzidas na safra 2004-2005 e destinadas ao mercado externo. 


\section{CONCLUSÕES}

A micoflora de sementes comerciais de braquiária é constituída por FSA e FP. Entre os primeiros, destacam-se Aspergillus sp. e Rhizopus sp., e entre os últimos, Bipolaris sp., Fusarium sp. e Phoma sp. Estes FP também são predominantes nos lotes de sementes com alta pureza física. Embora existam diferenças entre os lotes comerciais quanto à qualidade sanitária das sementes, nenhuma das respectivas regiões produtoras se destaca.

\section{AGRADECIMENTOS}

À Fundação de apoio ao Desenvolvimento do Ensino, Ciência e Tecnologia do Estado de Mato Grosso do Sul (Fundect-MS), à Fundação Manoel de Barros (FMB-MS) e ao Conselho Nacional de Desenvolvimento Científico e Tecnológico (CNPq), pelo apoio financeiro à pesquisa. À Embrapa Gado de Corte, pela oportunidade de realização do trabalho.

\section{REFERÊNCIAS}

ALVES, S.J.; DIAS, M.C.L. Contribuições da pesquisa à produção de sementes de espécies forrageiras - IAPAR. In: WORKSHOP SOBRE SEMENTES DE FORRAGEIRAS, 1., 1999, Sete Lagoas. Anais... Sete Lagoas: Embrapa Negócios Tecnológicos, 2000. p.73-80.

BARRETO, A.F.; EGBERTO, A.; BONIFÁCIO, B.F.; FERREIRA, O.R.R.S.; BELÉM, L.F. Qualidade fisiológica e a incidência de fungos em sementes de algodoeiro herbáceo tratadas com estratos de agave. Revista de Oleaginosas e Fibrosas, v.8, n.2/3, p.839-849, 2004.

BENCHIMOL, R.L; VERZIGNASSI, J.R.; POLTRONIERI, L.S.; SILVA, C.M.; PEREIRA, E.C.S. Pyricularia grisea: novo patógeno em Brachiaria brizantha cv. Marandu no Estado do Pará. Fitopatologia Brasileira, v. 31, p.201-202, 2006. (Resumo). Suplemento.

CAMPBELL, C.L.; MADDEN, L.V. Introduction to plant disease epidemiology. New York: WILEY \& Sons. 1990. 532p.

CIRIO, G.M.; LIMA, M.L.R.Z.C. Métodos de deteç̧ão do gênero Aspergillus em sementes de milho (Zea mays) em 270 dias de armazenamento. Visão Acadêmica, v.4, n.1, p.19-23, 2003.

CRUZ, C.D. Programa Genes: Aplicativo computacional em genética e estatística. Viçosa: UFV, 2001. 648p.

FARIAS, C.R.J.; LUCCA-FILHO, O.A.; PIEROBOM, C.R.; DEL PONTE, E.M. Qualidade sanitária de sementes de aveia-preta (Avena strigosa Schreb.) produzidas no estado do Rio Grande do Sul, safra 1999/2000. Revista Brasileira de Sementes, v.24, n.1, p.1-4, 2002.

FERNANDES, C.D.; MARCHI, C.E.; JERBA, V. de F.; BORGES, M. de F. Patógenos associados às sementes de forrageiras tropicais e estratégias de controle. In: ZAMBOLIM, L. (Ed.). Sementes: qualidade fitossanitária. Viçosa: UFV, 2005. p.183-213.

FIORAVANTI, M.C.S. Incidência, avaliações clínica, laboratorial e anatomopatológica da intoxicação subclínica por esporidesmina em bovinos. 1999. 256f. Tese (Doutorado em Medicina Veterinária) - Faculdade de Medicina Veterinária e Zootecnia, Universidade Estadual Paulista, Botucatu, 1999.

GARCÍA D.; S.X.; PINEDA, B. Reconocimiento de enfermedades fungosas transmitidas por semilla en germoplasma de Brachiaria spp. Fitopatología Colombiana, v.24, p.39-46, 2000.

LASCA, C.C.; VECHIATO, M.H.; KOHARA, E.Y. Controle de fungos de sementes de Brachiaria spp.: eficiência de fungicidas e influência do período de armazenamento de sementes tratadas sobre a ação desses produtos. Arquivos do Instituto Biológico, São Paulo, v.71, n.4, p.465-472, 2004.

MARCHI, C.E.; FERNANDES, C.D.; JERBA, V. de F.; TRENTIN, R.A.; BUENO, M.L.; GUIMARÃES, L.R. de A.; FABRIS, L.R. Sementes de forrageiras tropicais: patógenos associados e estratégias de controle. In: SIMPÓSIOBRASILEIRODE PATOLOGIA DESEMENTES, 9., 2006a, Passo Fundo. Anais. Passo Fundo, 2006a. (CD-ROM).

MARCHI, C.E.; FREITAS, M. de F.; ARIAS, A.M.S.; FERNANDES, C.D.; JERBA, V. de F.; BUENO, M.L. Patologia de sementes de forrageiras tropicais. Summa Phytopathologica, v.32, p.81, 2006b. (Resumo). Suplemento.

MARCHI, C.E.; FERNANDES, C.D.; FABRIS, L.R.; JERBA, V. de F.; SORGATTO, M. Incidência de Ustilago operta em sementes comerciais de braquiária. Summa Phytopathologica, v.33, p.75, 2007. (Resumo). Suplemento.

MARCHI, C.E.; FERNANDES, C.D.; ANACHE, F.C.; FABRIS, L.R. Progresso e controle da mela-dassementes de Brachiaria brizantha. Summa Phytopathologica, v.34, p.241-247, 2008.

MARTINS, L.; SILVA, W.R.; ALMEIDA, R.R. Sanidade em sementes de Brachiaria brizantha (Hochst.ex A.Rich) Stapf submetidas a tratamentos térmicos e químico. Revista Brasileira de Sementes, v.23, p.117-120, 2001.

MENTEN, J.O.M. Prejuízos causados por patógenos associados às sementes. In: MENTEN, J.O.M. (Ed.). Patógenos em sementes: detecção, danos e controle químico. São Paulo: Ciba Agro, 1995. p.115-136. 
MICHAELSKI, M.V.; CHARCHAR, J.d' A.; ANJOS, J.R.N. dos; FERNANDES, F.D.; SILVA, M.S.; SILVA, W.A.M. Transmissão de fungos de sementes para plântulas de Panicum maximum. In: ENCONTRO DE JOVENS TALENTOS DA EMBRAPA CERRADOS, 3., 2007, Planaltina. Documentos. Planaltina: Embrapa Cerrados, 2007. Resumo n.176.

MORAES, M.H.D.; GRAVENA, J.C.; MARUOKA, A.; MENTEN, J.O.M.; SALVO, S.; ZAMBON, S. Qualidade de sementes de Brachiaria brizantha tratadas e armazenadas. Summa Phytopathologica, v.32, p.80, 2006. Suplemento.

NEERGAARD, P. Seed pathology. London: The Macmillan, 1979. v.1, 839p.

PIEROBOM, C.R.; DEL PONTE, M.E. Manual de sanidade de sementes. Disponível em: <http://faem.ufpel.edu.br / dfs/patologiasementes/cgi-bin/sementes/ procura.cgi>. Acesso em: 29 set. 2008.

SAS INSTITUTE. SAS/STAT Software: changes and enhancements through release 6.12. Cary, NY. 1997.

SCOTT, A.J.; KNOTT, M.A. Cluster analysis method for rouping means in the analysis of variance. Biometrics, v.30, p.507-512, 1974
SILVA, M.G.F.; COSTA, J.S.; EZEQUIEL JUNIOR, S.M.; JESUS, L.A.M.; CORDEIRO, L.A.M.; PAZ LIMA, M.L. Qualidade fisiológica e sanitária de espécies comerciais de Brachiaria. Fitopatologia Brasileira, v.31, p. 329-329, 2006. Suplemento.

SOARES, P.C.; MOTA, R.A.; TEIXEIRA, M.N. et al. Aspectos epidemiológicos e clínicos da intoxicação por Pithomyces chartarum em ovinos da raça Sta. Inês, no município de Gravatá, PE. Revista Brasileira de Ciência Veterinária, v.7, n.2, p.78-82, 2000.

TANAKA, M.A. de S.; MAEDA, J.A.; PLAZAS, I.H. de A.Z. Microflora fúngica de sementes de milho em ambientes de armazenamento. Scientia Agricola, v.58, n.3, p.501-508, 2001.

VECHIATO, M.H. Sanidade de gramíneas forrageiras. In:SIMPÓSIO BRASILEIRODE PATOLOGIA DE SEMENTES, 8., 2004, João Pessoa. Anais. João Pessoa, 2004. p.55-57.

Recebido em 18/3/09

Aceito em 6/12/09 